\title{
Construção e validação da escala indisciplina escolar percecionada por alunos (eiepa)
}

\section{Construction and validation of the scale of indiscipline school perceived by students -EIEPA}

\author{
Fernando Manuel Videira dos Santos \\ Universidade de Coimbra
}

\begin{abstract}
Resumo
Estudo empírico incluindo um estudo preliminar relativo à construção e à validação da, Escala Indisciplina Escolar Percecionada por alunos (EIEPA), público-alvo os alunos que frequentam o $3^{\circ} \mathrm{CEB}$ pesquisa não-experimental com características descritivas, estudos de correlação e explicativas, a amostra constituída por 772 jovens, índice Alpha de Cronbach $(0,960)$, o coeficiente de SpearmanBrown $(0,911)$, coeficiente de correlação de Split-half $(0,939)$, estabilidade temporal $(r=0,931)$ e $(p=0,000), 4$ fatores com raízes latentes Eigenvalues superiores a 1,00 que explicam $(55,749 \%)$ da variância, com um resultado de Alpha de Cronbach para o total da escala (EIEPA) de $(0,960)$ o que é considerado muito bom.

Palavras-chave: Indisciplina escolar, gravidade, violência, aluno.
\end{abstract}

\begin{abstract}
An empirical study including a preliminary study on the construction and validation of the Student-Perceived Student Discipline Scale, the target audience of students attending the $3^{\circ} \mathrm{CEB}$ non-experimental research, with descriptive characteristics, correlation and explanatory studies, the sample constituted by 772 young, Cronbach Alpha index (0.960) Spearman-Brown coefficient (0.911) correlation coefficient of Split-half, (0.939), temporal stability $(\mathrm{r}=0.931)$ and $(\mathrm{p}=0.000), 4$ factors with roots Latent "Eigenvalues", higher than 1.00 that explain $(55,749 \%)$ the variance with a Cronbach Alpha result for the total scale (EIEPA) of (0.960) which is considered very good.

Keywords: School discipline, gravity, violence, student.
\end{abstract}

\section{Introdução}

A opção de construção e validação de uma escala com estas caraterísticas deveu-se ao facto de não termos conhecimento de um instrumento desta natureza aferido para a população Portuguesa que permitisse avaliar de forma específica a perceção dos comportamentos indisciplinados no seio da escola pelos alunos do $3^{\circ}$ ciclo do ensino básico português, pelo que foi por nós considerado importante e pertinente fazer este estudo empírico que correspondeu ao estudo métrico de um instrumento que avaliasse as variáveis referenciadas e permitisse a sua manipulação científica junto da população portuguesa desta faixa etária. Pretendíamos avaliar a perceção dos comportamentos indisciplinados, e a graduação das respostas foi feita numa escala de medida tipo "Likert" de quatro pontos cuja configuração era de, Muito grave (1); Grave (2); Pouco Grave (3) e Sem Gravidade (4). A uma pontuação mais elevada obtida pelo respondente corresponde a uma perceção da gravidade dos atos de indisciplina mais baixa, tendo em conta a pontuação que lhe foi atribuída

\section{Caraterísticas gerais da amostra}

A amostra é constituída por 772 jovens adolescentes que frequentavam a escola pública portuguesa no $3^{\circ}$ ciclo do ensino básico. Esta serviu e ajudou-nos no processo de construção do instrumento. Uma descrição mais detalhada da composição desta amostra tendo em conta a sua distribuição por, idade, género, área de residência, ano de escolaridade e classe socioeconómica de pertença, está bem exposta no quadro 1, que de seguida apresentamos. 
Quadro 1 - Características gerais da amostra utilizada no estudo psicométrico do instrumento

\begin{tabular}{|c|c|c|c|}
\hline & & $N(=772)$ & $\%$ \\
\hline \multicolumn{4}{|c|}{ Idade } \\
\hline \multicolumn{2}{|c|}{12} & 183 & 23,7 \\
\hline \multicolumn{2}{|c|}{13} & 272 & 35,2 \\
\hline \multicolumn{2}{|c|}{14} & 229 & 29,7 \\
\hline \multicolumn{2}{|c|}{15} & 61 & 7,9 \\
\hline \multicolumn{2}{|c|}{16} & 24 & 3,1 \\
\hline \multicolumn{2}{|c|}{17} & 3 & 0,4 \\
\hline M & \multicolumn{3}{|l|}{$\mathrm{Dp}$} \\
\hline 13,34 & \multicolumn{3}{|l|}{1,04} \\
\hline \multicolumn{4}{|c|}{ Género } \\
\hline \multicolumn{2}{|c|}{ Mulheres } & 402 & 52,1 \\
\hline \multicolumn{2}{|c|}{ Homens } & 370 & 47,9 \\
\hline \multicolumn{4}{|c|}{ Área de Residência } \\
\hline \multicolumn{2}{|c|}{ Rural } & 395 & 51,2 \\
\hline \multicolumn{2}{|c|}{ Urbana } & 377 & 48,8 \\
\hline \multicolumn{4}{|c|}{$\begin{array}{l}\text { Ano de escolaridade que } \\
\text { frequentam os sujeitos }\end{array}$} \\
\hline \multicolumn{2}{|c|}{$7^{\circ}$} & 322 & 41,7 \\
\hline \multicolumn{2}{|c|}{$8^{\circ}$} & 231 & 29,9 \\
\hline \multicolumn{2}{|c|}{$9^{\circ}$} & 219 & 28,4 \\
\hline \multicolumn{4}{|c|}{ Classe Socioeconómica } \\
\hline Classe I & sse Alta & 36 & 4,7 \\
\hline Classe II - C & Média Alta & 253 & 32,8 \\
\hline Classe III & se Média & 374 & 48,4 \\
\hline Classe IV - C & Média Baixa & 103 & 13,3 \\
\hline Classe V & se Baixa & 6 &, 8 \\
\hline
\end{tabular}

Pela análise dos resultados verificámos que, quanto às idades, a média é de 13,34 anos e o desvio padrão é de 1,04 .

Poderemos constatar ainda que a amostra no que respeita ao género dos sujeitos é, na sua maioria, constituída por sujeitos do género feminino 402 sujeitos a que corresponde um valor de $(52,1 \%)$, e os sujeitos do género masculino perfazem 370 sujeitos a que corresponde uma percentagem de, $(47,9 \%)$. No que respeita à zona de residência, poderemos observar que maioritariamente os sujeitos residem no meio rural a que corresponde um valor de $(51,2 \%)$, ao passo que os que residem na zona urbana corresponde a $(48,8 \%)$. Relativamente ao ano de frequência escolar, poderemos dizer que os alunos que frequentam o $7^{\circ}$ ano de escolaridade são 322 sujeitos a que corresponde $(41,7 \%)$, seguida pelos alunos que frequentam o $8^{\circ}$ ano, 231 sujeitos com um valor em percentagem de $(29,9 \%)$, e os alunos que frequentam o $9^{\circ}$ ano são 219 sujeitos a que corresponde um valor percentual de, $(28,4 \%)$. No que diz respeito à classe social de pertença, poderemos constatar que maioritariamente pertencem à classe socioeconómica III - (Classe Média - 48,4\%), seguemse os da classe socioeconómica II - (Classe Média Alta $32,8 \%$ ), seguem-se os da classe socioeconómica IV (Classe Média Baixa - 13,3\%), seguem-se os da Classe I
- (Classe Alta 4,7\%) e por fim os da classe V - (Classe Baixa $0,8 \%$ ) dos respondentes.

Escala indisciplina escolar percepcionada por alunos - estudo de fiabilidade e consistência interna

O quadro 2, dá-nos conta das correlações obtidas, positivas e significativas entre cada item e a nota global quando esta não contém esse item específico.

Quadro 2 - Escala Indisciplina Escolar Percepcionada por Alunos (EIEPA), - Consistência interna

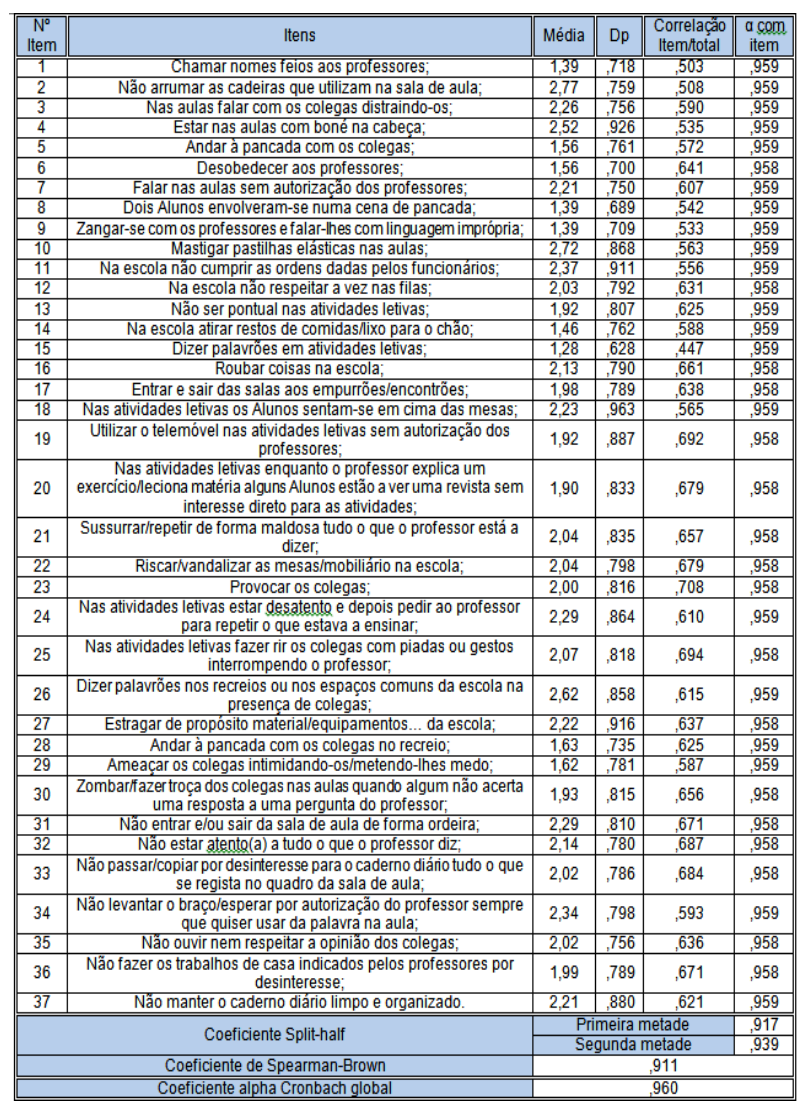

Assim, poderemos ficar com a perceção da forma como cada variável (item) se combina com o todo do instrumento. A este propósito, convém relembrar que as correlações mais relevantes são as que se referem à correlação do item com a nota global quando esta não contém esse item específico. Relativamente ao estudo da consistência interna do instrumento que construímos (EIEPA), este revelou ser um instrumento de medida com muito bom grau de homogeneidade. Como podemos apurar e está plasmado no quadro 2 , todos os valores das correlações cumprem o critério de Streiner e Norman (1989), segundo o qual se pode considerar a aceitação de todos os itens que apresentem uma correlação superior a $(0,20)$ com a nota global quando esta não contém o item. Relativamente aos valores de Alpha de Cronbach verificámos que todos são bastantes superiores a $(0,50)$ o que constitui o valor limite para a sua aceitabilidade. Os valores apontam para uma escala com uma consistência interna muito boa. 
Quadro 3 - Escala Indisciplina Escolar Percepcionada por Alunos (EIEPA), - Consistência Interna

\begin{tabular}{cc}
\hline Indicadores & Valores \\
\hline Coeficiente de Cronbach &, 960 \\
Coeficiente de Spearman-Brown &, 911 \\
Correlação Split-half &, 939 \\
\hline
\end{tabular}

Como é possível constatar no quadro 3, o índice Alpha de Cronbach apresenta um valor sugestivo de uma, muito boa consistência interna, sendo que, o valor encontrado para o coeficiente de Spearman-Brown se revela igualmente bastante bom e no que diz respeito ao coeficiente de correlação de Split-half, este indicador é igualmente revelador de uma boa consistência interna.

\section{Estabilidade temporal}

O estudo da fiabilidade da escala foi desenvolvido através da determinação da sua estabilidade temporal. Os valores aceitáveis de teste-reteste, aponta o valor de, 0,7 como valor mínimo aceitável.

Quadro 4 - Escala Indisciplina Escolar Percepcionada por Alunos (EIEPA), - Estabilidade temporal

\begin{tabular}{ccc}
\hline & $\mathbf{r}$ & $\mathbf{p}$ \\
\hline Total da Escala &, 931 & $\mathbf{, 0 0 0}$ \\
\hline
\end{tabular}

Aplicámos este teste num subgrupo de 124 alunos que já haviam respondido à escala e foi repetida a sua passagem com um intervalo posterior de 4 semanas. A correlação encontrada é indicativa de que a escala possui boa estabilidade temporal com um nível de significância muitíssimo significativo $(0,931)$.

\section{Análise fatorial}

O valor de KMO obtido foi $(0,972)$ o que mostra que há uma correlação muito boa entre as variáveis, o que, segundo a opinião de, Maroco (2011) é avaliado como, muito boa. Tendo em conta os valores obtidos podemos progredir com esta análise. Também o resultado do teste de esfericidade de Bartlett forneceu um valor de $\left(\chi^{2}=\right.$ $15754,056)$, tendo associado um nível de significância de $(0,000)$ o que leva à rejeição da hipótese da matriz das correlações na amostra ser uma identidade mostrando que existe correlação entre algumas variáveis. Também na opinião de Maroco (2011), o teste de esfericidade de Bartlett testa a hipótese da matriz das correlações ser a matriz de identidade. Verificámos que há correlação entre as variáveis $(\mathrm{Sig}=0,000)$. Caso tal não se verificasse dever-se-ia reconsiderar a utilização deste modelo fatorial, o que não é o caso.

Assim, uma vez confirmada a possibilidade de utilização da análise fatorial através do teste de esfericidade de Bartlett e da medida de adequação da amostra KMO, este procedimento técnico foi realizado com toda a confiança.

A solução fatorial final encontrada permitiu a seleção de 4 fatores, com raízes latentes "Eigenvalues", superiores a 1,00 que no seu conjunto explicam $(55,749 \%)$ da variância com um resultado de Alpha de
Cronbach apurado para o total da escala (EIEPA) de $(0,960)$ o que é considerado muito bom.

Assim poderemos verificar que do $1^{\circ}$ fator fazem parte 11 itens, do $2^{\circ}$ fator são 9 os itens que o constituem, do $3^{\circ}$ fator fazem parte 8 itens e do $4^{\circ}$ são 5 os itens que o formam, como vamos constatar nos quadros que se seguem.

Quadro 5 - Escala Indisciplina Escolar Percepcionada por Alunos (EIEPA), - fatores ortogonais originados após análise fatorial

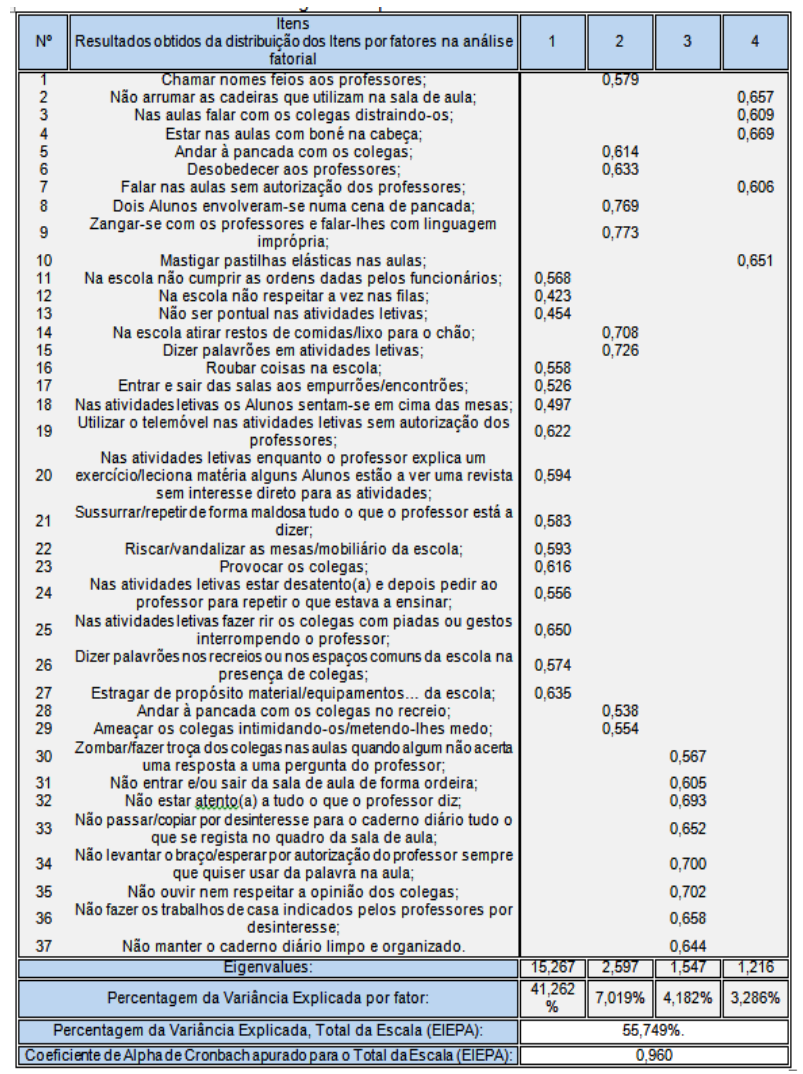

\section{Itens e Resultados fator 1 - Desobediência transgressão}

Verificámos que o fator 1 - Desobediência Transgressão em termos de Eigenvalues o valor é de $(15,267)$. Quanto à variância explicada, fator 1 (D. T.) ela é de, $(41,262 \%)$ e o valor de Alpha de Cronbach apurado foi $(0,925)$.

Diremos que o fator 1 - visa avaliar o nível de perceção da gravidade dos sujeitos em comportamentos indisciplinados de desobediência e transgressão relativos às disposições dadas pelos professores, funcionários quer da escola, bem como à transgressão de regras de convivência social que prejudicam o ambiente das salas de aula e da escola, bem como, prejudicam um ambiente salutar para que se possa aprender e/ou ensinar em contexto escolar. 
Quadro 6 - Escala Indisciplina Escolar Percepcionada por Alunos (EIEPA), - os itens e respetivos valores referentes ao Fator 1 - Desobediência Transgressão.

\begin{tabular}{|c|c|c|c|c|c|}
\hline Itens & $\begin{array}{l}\text { Itens que constituem o Fator } 1 \text { Desobediência Transgressão } \\
\text { Resultados obtidos da distribuicăo dos Itens por fatores na } \\
\text { analilise fatorial }\end{array}$ & 1 & 2 & 3 & 4 \\
\hline 11 & Na escola năo cumprir as ordens dadas pelos funcionários; & \multicolumn{4}{|l|}{0,568} \\
\hline 12 & $\begin{array}{l}\text { Na escola não respeitar a vez nas filas; } \\
\text { Não ser pontual Inas atvididades letivas: }\end{array}$ & \multicolumn{4}{|l|}{$\begin{array}{l}0,423 \\
0,454\end{array}$} \\
\hline $\begin{array}{l}13 \\
16\end{array}$ & $\begin{array}{l}\text { Năo ser pontual nas attiviadades letivas; } \\
\text { Roubar coisas na escola; }\end{array}$ & \multicolumn{4}{|l|}{0,558} \\
\hline 17 & Entrar e sair das salas aos empurrōées/encontrōes; & \multicolumn{4}{|l|}{0,526} \\
\hline 18 & $\begin{array}{l}\text { Nas atividades letivas os Alunos sentam-se em cima das } \\
\text { mesas; }\end{array}$ & \multicolumn{4}{|l|}{0,497} \\
\hline 19 & $\begin{array}{l}\text { Utilizar o telemóvel nas atividades letivas sem autorizaçäo dos } \\
\text { professores; }\end{array}$ & \multicolumn{4}{|l|}{0,622} \\
\hline 20 & $\begin{array}{l}\text { Nas atividades letivas enquanto o professor explica um } \\
\text { exercicioleciona matéria algunns Alunos estáo a ver uma } \\
\text { revista sem interesse direto para as ativididades: }\end{array}$ & \multicolumn{4}{|l|}{0,594} \\
\hline 21 & $\begin{array}{l}\text { Sussurrar/repetir de forma maldosa tudo o que o professor está } \\
\text { a dizer }\end{array}$ & \multicolumn{4}{|l|}{0,583} \\
\hline 22 & 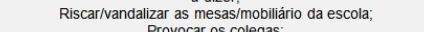 & \multirow{2}{*}{\multicolumn{4}{|c|}{$\begin{array}{l}0,593 \\
0,616\end{array}$}} \\
\hline 23 & $\begin{array}{l}\text { Provocar os colegas; } \\
\text { ? }\end{array}$ & & & & \\
\hline 24 & $\begin{array}{l}\text { Nas atividades letivas estar desatentota(a) e depois pedir ao } \\
\text { professor para repetir o oue estava a ensinar: }\end{array}$ & \multicolumn{4}{|l|}{0,556} \\
\hline 25 & $\begin{array}{l}\text { Nas atividades letivas fazer rir os colegas com piadas ou } \\
\text { gestos interrompendo o professor; }\end{array}$ & \multicolumn{4}{|l|}{0,650} \\
\hline 26 & $\begin{array}{l}\text { Dizer palavröes nos recreios ou nos espaços comuns da } \\
\text { escola na presenca de colegas: }\end{array}$ & \multicolumn{4}{|l|}{0,574} \\
\hline 27 & $\begin{array}{l}\text { escola na presencaca de colegas; } \\
\text { Estragar de propósito material/equipamentos... da escola. }\end{array}$ & \multicolumn{4}{|l|}{0,635} \\
\hline \multicolumn{2}{|r|}{ Eigenvalues: } & \multicolumn{4}{|l|}{15,267} \\
\hline \multirow{2}{*}{\multicolumn{2}{|c|}{$\begin{array}{l}\text { Percentagem da Varaianncia Explicada para o fator } 1 \text { - (D. T.): } \\
\text { Percentagem da Variância Explicada - Total da Escala (EIEPA): }\end{array}$}} & $41,262 \%$ & & & \\
\hline & & \multicolumn{4}{|c|}{$55,749 \%$} \\
\hline \multicolumn{2}{|r|}{ Coeficiente de Alpha de Cronbach apurado para o fator 1 - (D. T.) } & \\
\hline
\end{tabular}

\section{Resultados para o fator 2 - Relacionamento interpessoal}

Verificámos que o fator 2 - Relacionamento Interpessoal, em termos de Eigenvalues atingiu o valor de $(2,597)$. Quanto à variância explicada por este fator 2 (RI) é de, $(7,019 \%)$ e o valor de Alpha de Cronbach apurado foi $(0,891)$. Poderemos verificar ainda que o bloco de itens agrupados no fator 2 (RI) sugerem congregar comportamentos que apontam para comportamentos de relacionamento interpessoal. Isto é, os alunos enquanto atores organizacionais se praticam este tipo de comportamentos, revelam ter dificuldades de se relacionar quer com os outros, de uma forma direta ou indireta, isto é, têm dificuldades de aferir que a prática destes comportamentos na organização escolar pode prejudicar esse relacionamento interpessoal na escola.

Quadro 7 - Escala Indisciplina Escolar Percepcionada por Alunos (EIEPA), Itens e respetivos valores referentes ao fator 2 - Relacionamento Interpessoal

\begin{tabular}{|c|c|c|c|c|c|}
\hline \multicolumn{2}{|r|}{$\begin{array}{l}\text { Itens que constituem o fator } 2 \text { Relacionamento Interpessoal } \\
\text { Resultados obtidos da distribuicăoa dos Itens por fatores na analise fatorial }\end{array}$} & 1 & 2 & 3 & 4 \\
\hline & & \multicolumn{4}{|c|}{0,579} \\
\hline & Andar à pancada com os colegas; & \multirow{2}{*}{\multicolumn{4}{|c|}{0}} \\
\hline & 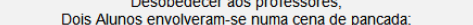 & & & & \\
\hline & Zangar-se com os professores e falar-lhes com linquagem impróoria: & \multicolumn{4}{|c|}{$\begin{array}{l}0,769 \\
0,773\end{array}$} \\
\hline & $\begin{array}{l}\text { Na escola atirar restos de comidas/lixo para o chão; } \\
\text { contia, }\end{array}$ & \multirow{2}{*}{\multicolumn{4}{|c|}{$\begin{array}{l}0,708 \\
0,726\end{array}$}} \\
\hline & Dizer palavrōes em atividades letivas; & & & & \\
\hline & Andar à pancada com os colegas no recreio; & \multirow{2}{*}{\multicolumn{4}{|c|}{0,538}} \\
\hline \multirow{2}{*}{\multicolumn{2}{|c|}{$\begin{array}{c}\text { Eigenvalues } \\
\end{array}$}} & \\
\hline & & & & & \\
\hline & $\begin{array}{l}\text { Percentagem da a ariancial Explicada para o fator } 2 \text { (RI) } \\
\text { Percentagem da Variância Explicada - Total da Escala (EIEPA) }\end{array}$ & \multicolumn{4}{|c|}{$55,749 \%$} \\
\hline & Alpha de Cronbach apurado para o fator 2 (RI) & \\
\hline
\end{tabular}

\section{Resultado para o fator 3 - Distração desinteresse}

Depois de ter sido efetuada a análise fatorial o fator 3 - Distração Desinteresse, verificámos que, em termos de Eigenvalues o mesmo obtém o valor de $(1,547)$. Quanto à variância explicada ela é de, $(4,182 \%)$ e o valor de Alpha de Cronbach apurado é de, $(0,903)$. Diremos que o Fator 3 - visa avaliar os comportamentos indisciplinados que sugerem a distração por parte dos sujeitos nas aulas sugerindo ainda que os mesmos promovem essa distração nos outros alunos e ainda, a falta de interesse pelos trabalhos escolares tanto os que decorrem no interior das salas de aula, bem como, os trabalhos que são indicados pelos professores para serem realizados em casa. Este tipo de comportamentos prejudica o ambiente das salas de aula e da escola bem como um ambiente propício às aprendizagens. Tudo isto pode ser constatado no quadro que se segue:

Quadro 8 - Escala Indisciplina Escolar Percepcionada por Alunos (EIEPA), - Itens e respetivos valores referentes ao Fator 3 - Distração Desinteresse

\begin{tabular}{|c|c|c|c|c|c|}
\hline $\mathrm{N}^{\circ}$ & $\begin{array}{l}\text { Itens que constituem o Fator } 3 \text {-Distraçăo Desinteresse } \\
\text { Resultados obtidos da distribuiçăo dos Itens por fatores na análise } \\
\text { fatorial }\end{array}$ & 1 & 2 & 3 & 4 \\
\hline & Zombar/fazer troça dos colegas nas aulas quando algum nẫo & \multirow{2}{*}{\multicolumn{4}{|c|}{0,567}} \\
\hline 31 & $\begin{array}{l}\text { acerta uma resposta a uma pergunta do professor, } \\
\text { Não entrar e/ou sair da sala de autla de forma ordeira. }\end{array}$ & & & & \\
\hline & Não estar atento(a) a tudo o que o professor diz; & \multicolumn{4}{|c|}{$\begin{array}{l}0,605 \\
0,693\end{array}$} \\
\hline & Não passar/copiar por desinteresse para o caderno diário tudo o & \multicolumn{4}{|c|}{0,652} \\
\hline & Não levantar o braço/esperar por autorizaçăo do professor sempre & \multirow{2}{*}{\multicolumn{4}{|c|}{0,700}} \\
\hline & que quiser usar da palavra na aula; & & & & \\
\hline 35 & Não ouvir nem respeitar a opiniäo dos colegas; & \multicolumn{4}{|c|}{0,702} \\
\hline 36 & $\begin{array}{l}\text { Não fazer os trabalhos de casa indicados pelos professores por } \\
\text { desinteresse: }\end{array}$ & \multicolumn{4}{|c|}{0,658} \\
\hline 37 & Não manter o caderno diário limpo e organizado. & \multicolumn{4}{|c|}{0,644} \\
\hline & Eigenvalues: & \multicolumn{4}{|c|}{1,547} \\
\hline & Percentagem da Variância Explicada para o fator $3(\mathrm{D} D)$ : & \multicolumn{4}{|c|}{$4,182 \%$} \\
\hline & Percentagem da Variância Explicada, Total da Escala (EIEPA): & \multicolumn{4}{|c|}{$55,749 \%$} \\
\hline & Alpha de Cronbach apurado para o fator $3(\mathrm{D} \mathrm{D})$ : & \multicolumn{4}{|c|}{$0,0,903$} \\
\hline
\end{tabular}

\section{Resultados para o fator 4 - Atitudes posturas}

Verificámos que o fator 4 em termos de Eigenvalues obtém o valor de $(1,216)$. Quanto à variância explicada é de, $(3,286 \%)$ e o valor de Alpha de Cronbach apurado para este fator foi de $(0,809)$. Diremos que o Fator 4 visa avaliar os comportamentos indisciplinados que sugerem Atitudes Posturas por parte dos sujeitos sugerindo ainda que os mesmos promovem essas Atitudes Posturas desrespeitando normas cívicas postuladas em regulamentos e normas internas das escolas que favorecem uma salutar convivência nas aulas, e a sua não observância prejudica o ambiente das salas de aula e da escola, bem como, um ambiente dedicado às aprendizagens na escola. Estes resultados podem, com mais detalhe, ser analisados no quadro que se seguida se apresenta:

Quadro 9 - Escala Indisciplina escolar Percepcionada por Alunos (EIEPA), -Itens e respetivos valores referentes ao Fator 4 - Atitudes Posturas

\begin{tabular}{|c|c|c|c|c|c|}
\hline $\mathrm{N}^{0}$ & $\begin{array}{l}\text { Itens que constituem } 0 \text { Fator } 4 \text { - Atitudes Posturas } \\
\text { Resultados obtidos da distribuiçăo dos Itens por fatores na } \\
\text { análise fatorial }\end{array}$ & 1 & 2 & 3 & 4 \\
\hline $\begin{array}{l}2 \\
3 \\
4 \\
7 \\
10 \\
\end{array}$ & $\begin{array}{l}\text { Não arrumar as cadeiras que utilizam na sala de aula; } \\
\text { Nas aulas falar com os colegas distraindo-os; } \\
\text { Estar nas aulas com boné na cabeça; } \\
\text { Falar nas aulas sem autorização dos professores; } \\
\text { Mastigar pastilhas elásticas nas aulas. }\end{array}$ & & & & $\begin{array}{l}0,657 \\
0,609 \\
0,669 \\
0,606 \\
0,651\end{array}$ \\
\hline & $\begin{array}{c}\text { Eigenvalues: } \\
\end{array}$ & & & & 1,216 \\
\hline & Percentagem da Variância Explicada para o fator 4 (AP): & & & & $3,286 \%$ \\
\hline & ercentagem da Variância Explicada, Total da Escala (EIEPA): & \multicolumn{4}{|c|}{$55,749 \%$} \\
\hline & Alpha de Cronbach apurado para o fator 4 (AP): & \multicolumn{4}{|c|}{0,809} \\
\hline
\end{tabular}

\section{Matriz de correlações}

Esta foi feita a partir da matriz de correlações entre as notas das quatro dimensões. A este propósito, refira-se que se as correlações forem demasiado elevadas o facto indica que os itens são redundantes. Isto é, não são sensíveis a aspetos diferentes do mesmo constructo, levando por isso, a que a escala perca em termos de validade de conteúdo como refere, Vaz Serra (1994 citado por Albuquerque (2004 p. 388). Analisadas as correlações de cada fator com as outras dimensões, 
verifica-se que as mesmas constituem quatro grupos. Assim, é possível verificar que, no fator F1 Desobediência transgressão, correlaciona-se positivamente e de forma muitíssimo significativa com os outros três fatores, fator F2 - Relacionamento interpessoal, com o F3 - Distração desinteresse; $F_{4}-$ Atitudes posturas e com o Total da Escala. O F2 Relacionamento interpessoal - (R. I.) correlaciona-se positivamente e de forma muitíssimo significativa com o F3 - Distração desinteresse - (D. D.); F4 - Atitudes posturas - (A. P.) e com o Total da Escala. O F3 Distração desinteresse - (D. D.) correlaciona-se positivamente e de forma muitíssimo significativa com F4 - Atitudes posturas - (A. P.) e com o Total da Escala.

Por fim, o F4 - Atitudes posturas - (A. P.) correlaciona-se positivamente e de forma muitíssimo significativa com o Total da Escala, como se apresenta no quadro 10 :

Quadro 10 - Matriz de correlações entre as pontuações da Escala Indisciplina Escolar Percepcionada por Alunos (EIEPA)

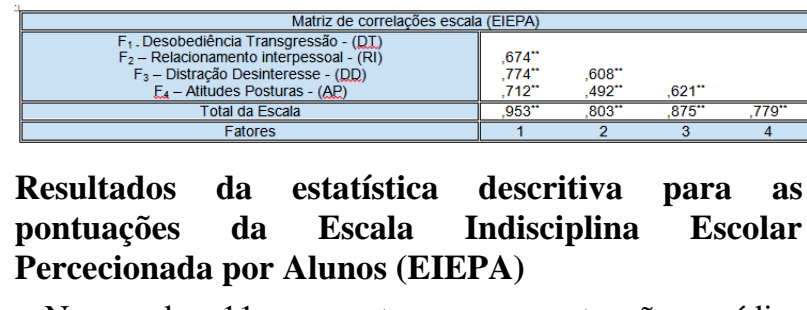

No quadro 11 apresentamos as pontuações médias para cada fator, os respetivos desvios padrão, bem como, o número de itens que fazem parte de cada um e o respetivos resultados para o total da escala. Como poderemos observar no quadro que se segue, a média global obtida pela amostra na escala construída e validada por nós foi de $(74,46)$ e o desvio padrão de $(18,995)$. Ficam aqui patentes os resultados obtidos pela nossa amostra uma vez que os mesmos nos conduziram à validação da Escala (EIEPA).

Quadro 11 - Estatística descritiva para as notas por fatores $e$ total da Escala Indisciplina Escolar Percepcionada por Alunos (EIEPA)

\begin{tabular}{|c||c|c||c|}
\hline Fatores & N`o de itens & Média & Dp \\
\hline \hline$F_{1}-$ Desobediência transgressão de regras & 15 & 31,76 & 8,882 \\
$F_{2}$ - Relacionamento interpessoal & 9 & 13,29 & 4,745 \\
$F_{3}$ - Distração desinteresse & 8 & 16,93 & 4,955 \\
E $_{A}$-Atitudes posturas & 5 & 12,48 & 3,067 \\
\hline Totalais & 37 & 74,46 & 18,995 \\
\hline
\end{tabular}

\section{Conclusão}

Apresentámos aqui um conjunto de resultados que sustentam quer do ponto de vista metodológico quer do ponto de vista estatístico a consistência desta escala.

Apresentámos também todos os passos que nos levaram à conceção e ao estudo empírico relativo à construção e à validação de uma escala a que chamámos, Escala Indisciplina Escolar Percecionada por alunos (EIEPA) que, tendo em conta os resultados obtidos revelou possuir caraterísticas psicométricas bastante robustas e adequadas para poder ser considerada instrumento de medida.

Apresentámos ainda um conjunto de resultados que sustentam quer do ponto de vista metodológico quer do ponto de vista estatístico a consistência desta escala.

Com efeito, depois de selecionados os itens iniciais, de verificada a validade de conteúdo de cada um, de inspecionada a interpretação dos inquiridos, de verificada a distribuição das respostas por item e ainda, de verificada a distribuição dos resultados, analisado o modo como os itens se agrupavam por construtos e de formadas as subescalas/dimensões, foi verificada a consistência interna e pode afirmar-se que, a versão definitiva do instrumento, forma uma escala com propriedades métricas muito boas.

Esta teve como público-alvo os alunos que frequentam o $3^{\circ}$ ciclo do ensino básico da escola pública portuguesa.

Com a conceção e validação desta escala tentámos dar resposta a uma lacuna que por nós foi observada uma vez que não encontrámos nenhuma escala com este propósito já construída e validada.

Assim, pensamos que com este passo estamos a dar e a contribuir para uma melhor compreensão desta problemática que é a indisciplina escolar. A construção e validação desta escala inaugura um campo para outros investigadores poderem alargar o espaço de investigação e de debate sobre esta problemática.

Se é verdade que a indisciplina escolar é um gigantesco problema na organização escolar, depois desta investigação, para nós, ficou mais clara, muito mais robusta a ideia de que não se pode trabalhar a problemática da indisciplina escolar com determinismos, com ideias pré-concebidas, quer sobre as suas causas, quer sobre os seus efeitos. Neste sentido, parece-nos que o melhor caminho a seguir para ajudar a minimizar esta problemática, que é preocupante, que é perturbadora da paz social nas escolas, que é socialmente injusta... é apostar no seu estudo multidisciplinar e polissémico para se compreender melhor e assim, em colaboração com todas as entidade presentes na Comunidade Educativa encontrar o melhor caminho para prevenir a sua ocorrência e para se apostar na sua redução em meio escolar. Ora esta escala pode fazer o seu caminho, pode, assim, ser mais um instrumento que pode dar o seu contributo para ajudar a melhorar a paz e a vida quotidiana das nossas escolas.

\section{Referências}

Aires, L. M. (2009). Disciplina na sala de aulas. Um guia de boas práticas para professores do $3^{\circ}$ ciclo do ensino básico e ensino secundário. Lisboa: Edições Sílabo.

Albuquerque, C. M. (2004). Comportamientos de salud y de riesgo en la adolescencia. Tese de Doutoramento não publicada. Badajoz: Universidade da Extremadura, Departamento de Psicologia e Educação.

Amado, J. (2010). Da indisciplina escolar ao cyberbullying. Portal de Ensino à distância. Coimbra: Universidade de Coimbra. 
Amado, J., \& Freire, I. P. (2009). A(s) indisciplina(s) na escola: Compreender para prevenir. Coimbra: Almedina.

Araújo, A. (2014). Diário de uma sala de aula. Duas professoras, quatro alunas e uma mãe. Lisboa: Fundação, Francisco Manuel dos Santos.

Avilés, J. M. (2013). Análisis psicosocial del cyberbullying. Claves para una educación moral. Papeles del psicólogo, Vol. 34 (1), pp. 6573.

Chaves, G. M. P. R. (2014). A escola face às manifestações de indisciplina: Estudo de caso sobre as dinâmicas organizacionais na resolução da indisciplina. Compreender e Prevenir. Coimbra: Almedina.

Chaves, G. M. P. R. (2014). A escola face às manifestações de indisciplina: Estudo de caso sobre as dinâmicas organizacionais na resolução da indisciplina. Compreender e Prevenir. Coimbra: Almedina.

Espelage, D., \& Lopes J. (2013). Indisciplina na Escola. Lisboa: Fundação, Francisco Manuel dos Santos.

Hora, et al. (2010). Confiabilidade em questionários para qualidade: Um Estudo com o coeficiente alfa de cronbach, vol. 11 (pp. 85-103). Produto \& Produção.

Maroco, J. (2007). Análise estatística com utilização do SPSS. ( $3^{\mathrm{a}}$ ed.). Lisboa: Edições Sílabo.

Maroco, J. (2011). Análise estatística com o SPSS Statistics. Report Number.

Maroco, João \& Garcia Marques, Teresa (2006). Qual a fiabilidade do alfa de Cronbach? Questões antigas e soluções modernas?. Laboratório de Psicologia. Vol. 4, no 1, p. 65-90.

Pestana, Maria Helena; Gageiro, João Nunes (2008). Análise de dados para ciências sociais: A complementaridade do SPSS. ( $5^{\mathrm{a}}$ ed. rev. e corrigida). Lisboa: Edições Sílabo.

Santos, F. (1998). Indisciplina Escolar: Representações dos professores, um estudo no Distrito da Guarda. Tese de Curso de Estudos Superiores Especializados não publicada. Porto: I.S.E.T..

Santos, F. (2006). Representações de encarregados de educação da gravidade de comportamentos indisciplinados dos alunos. Tese de Mestrado não publicada. Porto: Universidade Portucalense Infante D. Henrique.

Santos, F. (2010) Indisciplina escolar sua vivência e representações em adolescentes. Tesina não publicada. Salamanca: Universidade Pontifícia de Salamanca, Departamento de Ciências da Educação.

Santos, F. (2013). Indisciplina escolar uma questão problemática!?. Saarbrúcken: Novas Edições Académicas.

Santos, F. (2015) Indisciplina Escolar: Determinantes sociodemográficos, familiares, psicossociais, e de contexto escolar - um olhar sobre a indisciplina escolar. Tese de Doutoramento não publicada. Salamanca: Universidade Pontifícia de Salamanca, Departamento de Ciências da Educação.

Santos, F.\& Veiga F. H. (2006), Representações dos pais e encarregados de educação acerca dos comportamentos indisciplinados dos alunos, in Livro de Atas do XV Colóquio da AFIRSE/AIPELF Sessão Portuguesa. Portugal: Lisboa. 